\title{
Intervenções Psicopedagógicas e Tecnologias Digitais na Contemporaneidade
}

\author{
Silvana Corbellini, Luciane Magalhães Corte Real, Nathalia Silveira \\ Universidade Federal do Rio Grande do Sul - Faculdade de Educação \\ silvanacorbellini@gmail.com; luciane.real@ufrgs.br; \\ nathalia.silveira23@gmail.com
}

\begin{abstract}
The article presents the results of part of a research involving psychopedagogical interventions and digital technologies. The investigation was carried out after the publication of Completion Course of Work on a specialization course at Universidade Federal do Rio Grande do Sul in the years 2015 and 2016. The research was qualitative in the form of case study aimed to investigate what and how technologies have been used by educational psychologists. Mapped to the different technologies that were used and the results achieved. It was concluded that the practice of psycho-pedagogical together with the use of technology contributes significantly in the process of learning the subjects, acting as a playful component and facilitator in the interventions.
\end{abstract}

Resumo.O artigo apresenta os resultados do recorte de uma pesquisa que envolve intervenções psicopedagógicas e tecnologias digitais. A investigação foi realizada a partir da publicação dos Trabalhos de Conclusão de Curso em um Curso de Especialização da Faculdade de Educação da Universidade Federal do Rio Grande do Sul nos anos de 2015 e 2016. A pesquisa foi qualitativa na forma de estudo de caso cujo objetivo foi investigar quais e como as tecnologias foram utilizadas pelos psicopedagogos. Mapeou-se as diferentes tecnologias que foram utilizadas e os resultados alcançados. Conclui-se que a prática do psicopedagogo aliada ao uso das tecnologias contribui significativamente no processo de aprendizagem dos sujeitos, atuando como um componente lúdico e facilitador nas intervenções.

\section{Introdução}

As contribuições das tecnologias para as mais diversas áreas são hoje, elementos considerados indispensáveis. Não há espaço no qual as tecnologias não participem. Entre eles situa-se inclusive a Psicopedagogia, tanto em nível preventivo, quanto em pesquisas e curativo. As Tecnologias Digitais de Informação e Comunicação (TDIC) têm se mostrado instrumentos valiosos nesse contexto.

Assim, além da necessidade dos profissionais conhecerem as diversas TDIC, torna-se imprescindível saber dominar e aplicar. Há, ainda, pouca pesquisa específica ligando as tecnologias à área da Psicopedagogia. A demanda por inovações nessa área, 
V Congresso Brasileiro de Informática na Educação (CBIE 2016)

Anais dos Workshops do V Congresso Brasileiro de Informática na Educação (CBIE 2016)

para agregar as TDIC aos projetos nos mais diversos âmbitos requer trabalhos sistemáticos, com planejamentos, objetivos e avaliação de resultados. A importância de conhecermos as mais diversas ferramentas que estão sendo utilizadas e os resultados que os profissionais vêm alcançando é o que norteia este trabalho.

É preciso estar em constante atualização em qualquer área, procurando aprimorar e utilizar os diferentes recursos existentes, mas, isso implica em selecionar aqueles que irão atender às especificidades das demandas de cada área. As tecnologias estão presentes no cotidiano das pessoas. As crianças têm aprendido com elas e não podem mais ser ignoradas no seu potencial por aqueles que trabalham com aprendizagem. Assim, a formação de profissionais aptos a encarar as modificações impostas pelas tecnologias torna-se um componente vital do trabalho do psicopedagogo.

Diante da perspectiva do uso delas na psicopedagogia, este trabalho visa a apresentação de diferentes práticas que foram desenvolvidas e as suas implicações para o trabalho psicopedagógico. Para tanto, realizou-se um estudo de caso, no qual foram mapeados 88 trabalhos de conclusão do curso em um Curso de Especialização em Psicopedagogia e Tecnologias da Informação e Comunicação em uma universidade pública, elencando-se as tecnologias utilizadas, os objetivos propostos e os resultados apurados.

Inovar implica em interrogar o que está sendo feito e procurar novas formas de pensar e agir. Nesta pesquisa observou-se que não é preciso inventar coisas grandiosas, mas sim, que a utilização dos diversos recursos que se encontram disponíveis atualmente, pode e faz diferença nas intervenções psicopedagógicas, contribuindo significativamente para o desenvolvimento dos sujeitos.

\section{Psicopedagogia e os recursos tecnológicos}

As tecnologias nos fazem vislumbrar um horizonte de novas possibilidades. E abrem, também, um novo leque de dificuldades a serem superadas, o que implica em reflexões neste contexto atual sobre as práticas que englobam o uso das TICs. É inegável que as tecnologias são um grande aliado na área da educação, pois propiciam um vasto campo de conhecimentos, de novas interações, de participações mais interativas, entre outros. Um destes campos que podem ser beneficiados com a inserção das tecnologias é a Psicopedagogia.

A Psicopedagogia é um campo voltado para a compreensão dos processos de aprendizagem, nos diversos âmbitos - preventivo, diagnóstico e tratamento - em diferentes espaços, tais como escolas, ONGs, instituições, etc. Atualmente, não há mais dicotomia entre espaços de sala de aula ou outros espaços no que tange a aprendizagem. Pode-se aprender em qualquer tempo e em qualquer espaço.

A Psicopedagogia considera os aspectos intelectuais, afetivos e sociais. Pontua que para que a aprendizagem ocorra deve participar do processo "um equipamento biológico com disposições afetivas e intelectuais que interferem na forma da relação do sujeito com o meio, sendo que essas disposições influenciam e são influenciadas pelas condições socioculturais do sujeito e do seu meio" [Bossa, 2000, p. 24]. 
V Congresso Brasileiro de Informática na Educação (CBIE 2016)

Anais dos Workshops do V Congresso Brasileiro de Informática na Educação (CBIE 2016)

Pain (1989) aborda o problema da aprendizagem a partir de uma perspectiva multifatorial e afirma que em todo diagnóstico há uma hipótese inicial que requer a sua investigação em cada momento da relação com o sujeito. Salienta ele que precisa ser visto isto como um processo, podendo ser modificado a qualquer instante.

As intervenções psicopedagógicas visam trabalhar com a aprendizagem, seja no seu exercício efetivo de melhoria, ou seja, no sentido de minimizar ou superar dificuldades. Hoje, uma das questões que se destacam é em relação às contribuições que as tecnologias podem trazer à prática do psicopedagogo. As intervenções psicopedagógicas serão procedimentos específicos do profissional da psicopedagogia e englobarão a utilização de diversos instrumentos na avaliação dos sujeitos, tais como anamneses, entrevistas com alunos, pais e professores e observações em salas de aulas. As intervenções podem ser realizadas individualmente e/ou em grupo.

Os recursos tecnológicos vêm sendo explorados na cultura contemporânea conduzindo os mais diversos pesquisadores a investigar os seus aspectos lúdicos, atrativos e os impactos que causam na vida dos sujeitos. Desta forma, têm se evidenciado como aliados importantes para as mais diversas práticas profissionais, incluindo-se a do psicopedagogo.

Como apontam Jesus et al. (2015, p. 169):

Acredita-se que as atividades lúdicas são instrumentos
importantíssimos na relação ensino-aprendizagem se
acompanhadas de um arcabouço pedagógico e, num contexto
educacional. Elas possibilitam a formação de uma
aprendizagem mais significativa, pessoal e ao mesmo tempo
intrapessoal.

Valente (1997) refere que a utilização da tecnologia de uma maneira inteligente na área da educação pode promover a autonomia de professores e alunos, bem como flexibilizar o sistema tradicional da educação.

Kenski (2012) aponta a importância de que as tecnologias não sejam vistas como modismo, mas que se considere a relevância e o poder educacional transformador que elas possuem. Destaca a autora a necessidade do preparo dos profissionais para assumir novas perspectivas e contemplarem visões inovadoras de ensino e de escola, aproveitando-se das tecnologias.

De acordo com Real e Corbellini (2011, p.04) "a inserção de ferramentas tecnológicas podem fomentar uma aprendizagem interativa, na qual o discente torna-se o sujeito de sua aprendizagem", desenvolvendo a autonomia e o prazer de aprender.

Problematiza-se a questão da inserção das tecnologias nos processos de ensino e aprendizagem de maneira que realmente contribuam para o ensino nas escolas. Fistarol et al (2014, p. 218) afirmam que: "o ambiente escolar é um dos locais mais propícios para implementar estratégias de inclusão e acesso às TIC". Referem os autores que os conhecimentos que são adquiridos pelos alunos podem ser aliados com as TIC, de forma que o aprendizado torne-se mais prático e agradável. O psicopedagogo também pode e deve atuar neste processo de inclusão das tecnologias no ambiente escolar visando alterações significativas.

E, corroborando com esta questão, Benfica e Foohs afirmam: 
V Congresso Brasileiro de Informática na Educação (CBIE 2016)

Anais dos Workshops do V Congresso Brasileiro de Informática na Educação (CBIE 2016)

\begin{abstract}
O uso das mídias como um instrumento pedagógico é favorável para que as características, que se busca desenvolver nos educandos se efetivem, pois se acreditam que as ferramentas midiáticas agregadas aos conteúdos disciplinares, possam oportunizar ações de linguagem as quais os levarão à melhor produção, compreensão interpretação de conceitos que irão lhes auxiliar na interação comunicativa, social e comunicacional [Benfica, Foohs, 2014, p. 364].
\end{abstract}

O trabalho do psicopedagogo torna-se efetivo para subsidiar e integrar as tecnologias nos processos de ensino e aprendizagem, contribuindo com os docentes em seus planejamentos e nas atividades, gerando inclusão digital, pois estas ferramentas são vistas como importantes aliadas na educação. Para promover a inclusão digital, não basta fornecer a ferramenta, é preciso a compreender de como utilizá-la, exigindo que os profissionais estejam capacitados para o uso.

Conclui-se, desta forma, que o uso dos recursos nas intervenções psicopedagógicas requer necessidade de planejamento e pesquisa visando contribuir com o desenvolvimento das aprendizagens.

\title{
3.Metodologia
}

Trata-se de uma pesquisa qualitativa na forma de estudo de casos relativos a 88 trabalhos de conclusão de um curso de especialização ofertado nos anos de 2015 e 2016. Compreende-se Estudo de Caso conforme a definição de Yin (2010) como uma investigação empírica que envolva um método abrangente, considerando a lógica do planejamento, da coleta e da análise dos dados.

Este artigo é um recorte de uma pesquisa iniciada no ano de 2014 na Faculdade de Educação da Universidade Federal do Rio Grande do Sul. Estão sendo investigados 88 trabalhos de conclusão de um curso de especialização em Psicopedagogia em que foram utilizados TDIC com sujeitos que apresentavam dificuldades de aprendizagem e em situações nas quais foram desenvolvidos projetos preventivos na área. Nesse recorte o foco é investigar como as diversas tecnologias vêm sendo utilizadas nas intervenções da área da psicopedagogia. Realizou-se o mapeamento das ferramentas que foram utilizadas nas intervenções dos 88 trabalhos de conclusão do curso.

A coleta de dados foi realizada através da leitura de todos os trabalhos, identificando-se as tecnologias usadas. O objetivo geral foi o de mapear as tecnologias utilizadas nas intervenções psicopedagógicas e investigar se houve contribuições significativas no desenvolvimento dos sujeitos e grupos.

Os resultados do uso de cada ferramenta utilizada nas intervenções psicopedagógicas foram analisados procurando identificar se houve contribuição destes recursos a partir das intervenções psicopedagógicas.

Apresentou-se o mapeamento das tecnologias em uma tabela. Selecionaram-se cinco exemplos para ilustrar as intervenções psicopedagógicas realizadas com o uso das tecnologias e as suas contribuições efetivas. 
V Congresso Brasileiro de Informática na Educação (CBIE 2016)

Anais dos Workshops do V Congresso Brasileiro de Informática na Educação (CBIE 2016)

\section{Apresentação e análise dos dados}

Realizou-se a leitura dos 88 trabalhos de conclusão do curso de especialização. Os estudos englobam temas de leitura e escrita, matemática, inclusão digital, uso de blogs, uso de celulares e tablets, jogos digitais, entre outros. Destes trabalhos identificaram-se as ferramentas que foram utilizadas, os objetivos que eram propostos e os resultados que foram encontrados nas intervenções psicopedagógicas efetivadas. Alguns dos trabalhos não se limitaram ao uso de apenas uma ferramenta, compondo um conjunto de vários recursos para as intervenções.

Selecionaram-se os estudos de casos que envolveram as diferentes tecnologias utilizadas como recursos para as intervenções psicopedagógicas, em número de 49 casos. Excluíram-se os jogos digitais, por se apresentarem em um número de casos elevados (41 casos que desta forma), que pela relevância quantitativa justificavam a composição de outra pesquisa. Alguns trabalhos utilizaram mais de um recurso.

O objetivo das intervenções relatadas nos trabalhos foi o de atuar no processo de aprendizagem seja minimizando dificuldades, seja potencializando formas de aprendizagem, trabalhando sintomas e inibições e, também, trabalhando de forma preventiva.

Os trabalhos foram realizados em computadores, notebooks, tablets ou celulares como instrumento. A partir deles foram utilizadas diversas ferramentas, que foram identificadas e são discriminadas no seguinte quadro:

\begin{tabular}{|c|c|c|}
\hline Recursos tecnológicos & Frequência & Descrição das atividades \\
\hline $\begin{array}{l}\text { Computadores/Notebook/ } \\
\text { Tablet/Celular }\end{array}$ & 12 & Alicerces para as mais diversas atividades. \\
\hline Biblioteca Multimídia & 1 & $\begin{array}{l}\text { Visualizar trabalhos e conteúdos, realizar } \\
\text { pesquisas. }\end{array}$ \\
\hline $\begin{array}{l}\text { Sala de vídeo/ Vídeos / TV/ } \\
\text { DVD / Data show / } \\
\text { Podcast, } \\
\text { Software para gideoclips, } \\
\text { musical. }\end{array}$ & 19 & $\begin{array}{l}\text { Assistir e/ou elaborar vídeos, áudios, filmes; } \\
\text { realização de telejornais; material de apoio. }\end{array}$ \\
\hline Moodle & 1 & Atividade direcionada à formação de professores. \\
\hline Editor de texto word & 1 & Apoio à alfabetização infantil. \\
\hline Jogos digitais & 41 & $\begin{array}{llll}\begin{array}{l}\text { Atividades diversas } \\
\text { aprendizagens. }\end{array} & \text { com } & \text { objetivos } & \text { de }\end{array}$ \\
\hline Laboratório de informática & 10 & Espaço para exploração de diversos projetos. \\
\hline Máquina fotográfica & 1 & $\begin{array}{l}\text { Apoio para atividade de desenvolvimento da } \\
\text { autoestima. }\end{array}$ \\
\hline Webquests/ webgincana & 3 & $\begin{array}{l}\text { Pesquisas diversas na web e atividade de caça ao } \\
\text { tesouro. }\end{array}$ \\
\hline Audiobooks & 1 & Edição de livro falado. \\
\hline Tobii Communicator & 1 & $\begin{array}{l}\text { Software de comunicação alternativa para } \\
\text { intervenções com crianças autistas. }\end{array}$ \\
\hline Facebook / Whatsapp & 3 & $\begin{array}{l}\text { Criação de aplicativo para disciplina de } \\
\text { Matemática; Grupos de apoio. }\end{array}$ \\
\hline Paint & 3 & Edição de imagens \\
\hline HQs digitais/Pixel & 2 & Elaboração de textos explorados nos quadrinhos. \\
\hline
\end{tabular}


V Congresso Brasileiro de Informática na Educação (CBIE 2016)

Anais dos Workshops do V Congresso Brasileiro de Informática na Educação (CBIE 2016)

\begin{tabular}{|l|l|l|}
\hline Blog/pbwork & 4 & $\begin{array}{l}\text { Realização de jornal online, blogs de visualização } \\
\text { para comunidade de trabalhos realizados nos } \\
\text { grupos. }\end{array}$ \\
\hline Google Earth & 1 & $\begin{array}{l}\text { Atividade direcionada a aprendizagem da } \\
\text { disciplina de Geografia. }\end{array}$ \\
\hline
\end{tabular}

Quadro 1: Tics utilizadas como apoio as intervenções psicopedagógicas

Foram selecionados cinco trabalhos do universo desta pesquisa visando ilustrar as intervenções psicopedagógicas realizadas com apoio nos recursos tecnológicos, que são apresentados a seguir, citando-se os sujeitos, os recursos tecnológicos que foram utilizados, as intervenções psicopedagógicas e os resultados alcançados.

\begin{tabular}{|c|c|c|c|}
\hline Sujeitos & Recursos & Objetivos & Resultados \\
\hline $\begin{array}{l}\text { Professores } \\
\text { alunos de duas } \\
\text { turmas de Ensino } \\
\text { Médio. }\end{array}$ & $\begin{array}{l}\text { GPS e Google } \\
\text { Earth }\end{array}$ & $\begin{array}{l}\text { Avaliar as contribuições } \\
\text { do GPS e Google Earth } \\
\text { para aulas de Geografia. }\end{array}$ & $\begin{array}{l}\text { Os alunos passam a apreciar } \\
\text { as atividades propostas nas } \\
\text { aulas e perceber a ligação } \\
\text { com o meio no qual estão } \\
\text { inseridos. }\end{array}$ \\
\hline $\begin{array}{lr}\text { Menina } & \text { com } \\
\text { diagnóstico } & \text { de } \\
\text { Espectro Autista. }\end{array}$ & $\begin{array}{l}\text { Tobii } \\
\text { Communicator } \\
\text { (Software de } \\
\text { comunicação } \\
\text { alternativa) }\end{array}$ & $\begin{array}{lr}\text { Estratégias } & \text { para } \\
\text { melhoras } & \text { de } \\
\text { dificuldades } & \text { de } \\
\text { aprendizagem de criança } \\
\text { com Espectro Autista. }\end{array}$ & $\begin{array}{l}\text { Melhora na interação social, } \\
\text { na aprendizagem. Maior } \\
\text { sentimento de segurança, } \\
\text { capacidade de expressão e } \\
\text { motivação para as } \\
\text { atividades propostas. }\end{array}$ \\
\hline Aluno de $3^{\circ}$ ano & Aplicativo POU & $\begin{array}{lr}\text { Observação } & \text { da } \\
\text { interação, da afetividade } \\
\text { e de vínculos } \\
\text { desenvolvidos com o } \\
\text { animal de estimação } \\
\text { virtual promovendo a } \\
\text { melhora } \\
\text { dificuldades } \\
\text { aprendizagens. }\end{array}$ & $\begin{array}{l}\text { Estabelecimento de vínculo } \\
\text { entre aluno e professor; } \\
\text { maior interação com os } \\
\text { colegas; diminuição da } \\
\text { apatia e distanciamento; } \\
\text { maior empenho na } \\
\text { conclusão de tarefas. }\end{array}$ \\
\hline $\begin{array}{l}\text { Turma de alunos } \\
\text { do Ensino Médio. }\end{array}$ & $\begin{array}{l}\text { Vídeos com data } \\
\text { show } \\
\text { (telejornal) }\end{array}$ & $\begin{array}{lr}\text { Auxiliar } & \text { nas } \\
\text { dificuldades dos } & \text { alunos } \\
\text { no conteúdo } & \text { de } \\
\text { Termoquímica e } & \text { na } \\
\text { disciplina de Química. }\end{array}$ & $\begin{array}{l}\text { Maior compreensão dos } \\
\text { conteúdos; maior } \\
\text { autonomia; fortalecimento } \\
\text { dos laços devido ao trabalho } \\
\text { em grupo. }\end{array}$ \\
\hline $\begin{array}{l}\text { Turma de alunos } \\
\text { da disciplina de } \\
\text { Educação Física } \\
\text { do Ensino Médio } \\
\text { politécnico. }\end{array}$ & $\begin{array}{l}\text { Áudio de trilhas } \\
\text { sonoras, } \\
\text { celulares } \\
\text { câmaras para } \\
\text { filmagem de } \\
\text { ensaios, criação } \\
\text { de blog. }\end{array}$ & $\begin{array}{l}\text { Oportunizar a inovação } \\
\text { das aulas através da } \\
\text { dança e do uso das } \\
\text { tecnologias visando } \\
\text { maior integração entre } \\
\text { os alunos, sua } \\
\text { motivação e seu } \\
\text { desenvolvimento } \\
\text { criativo. }\end{array}$ & $\begin{array}{l}\text { Construção de } \\
\text { conhecimentos; maior } \\
\text { integração; familiarização } \\
\text { com o mundo virtual dentro } \\
\text { da perspectiva pedagógica. }\end{array}$ \\
\hline
\end{tabular}

Através do detalhamento desses estudos constata-se que os recursos tecnológicos selecionados para apoio às mais diversas intervenções psicopedagógicas, sejam 
V Congresso Brasileiro de Informática na Educação (CBIE 2016)

Anais dos Workshops do V Congresso Brasileiro de Informática na Educação (CBIE 2016)

singulares, sejam de grupos; sejam de cunho curativo, sejam preventivos; mostram-se como recursos que agregam para o alcance dos resultados esperados. Nestes exemplos, constata-se que os objetivos propostos lograram êxito.

Além destes cinco trabalhos apresentados, os outros 44 que foram mapeados também mostraram resultados significativos, tais como: maior interesse por parte dos alunos em relação às aprendizagens, maior autonomia, melhora de dificuldades de aprendizagem, mais interação entre alunos e alunos, alunos e professores, entre outros. As tecnologias como atrativos para as atividades em sala de aula, ou como intervenções psicopedagógicas singulares mostra-se como um consenso pelos usuários.

Estes dados, encontrados em relação aos múltiplos recursos tecnológicos explorados pelos psicopedagogos, confirmam pesquisas realizadas por diversos autores que afirmam ter ocorrido resultados satisfatórios no uso das tecnologias na educação (Kenski, 2007; Valente, 1993, 2013; Real e Corbellini, 2011; Fistarol et al., 2014; Benfica e Foohs, 2014). Estas pesquisas mostram que o uso de recursos tecnológicos é profícuo em diversas áreas, inclusive aquelas que englobam a aprendizagem.

\section{Conclusões}

O uso das tecnologias quando aplicadas à área da psicopedagogia podem contribuir para o desenvolvimento da aprendizagem, minimizar dificuldades e proporcionar outros benefícios, tais como maior interesse dos sujeitos pelas atividades, elevação da autonomia, socialização, trabalhos em equipe, etc.

Considerando a relevância das tecnologias na aprendizagem, no trabalho do psicopedagogo como um profissional dedicado ao processo da aprendizagem, questionam-se os usos das tecnologias na prática do psicopedagogo. Quais os recursos que estão sendo utilizados? Com qual finalidade? Quais as contribuições que apresentam?

Com esta pesquisa destacaram-se diversos usos possíveis de recursos tecnológicos em intervenções psicopedagógicas, e ressaltou-se que para os resultados serem alcançados é essencial que o profissional estabeleça os objetivos de forma clara, considerando as idiossincrasias de cada sujeito ou de cada turma. Não há recurso tecnológico que venha a resolver os problemas por si só, é necessário um profissional que tenha competência para utilizá-la em prol dos resultados perseguidos.

$\mathrm{O}$ uso das tecnologias aliadas às intervenções psicopedagógicas é um desafio. A formação de profissionais implica em contemplar conhecimentos e reflexões sobre estas ferramentas, pois hoje, elas acarretam mudanças significativas na aprendizagem dos sujeitos, Ocasionando grandes avanços e impondo novas dificuldades que precisam ser superadas. Desta forma, a formação deve contemplar um horizonte de possibilidades que as tecnologias proporcionam, ao mesmo tempo, que precisa refletir sobre as novas práticas que as incluem.

Assim, o uso das tecnologias no campo da Psicopedagogia implica em um cuidadoso planejamento, avaliando-se os objetivos e os resultados que se pretende alcançar. $O$ intuito é que as tecnologias sirvam como apoio ao trabalho psicopedagógico, como ferramentas que o profissional possa utilizar para o desenvolvimento da aprendizagem. Nesse contexto, as tecnologias podem servir como 
V Congresso Brasileiro de Informática na Educação (CBIE 2016)

Anais dos Workshops do V Congresso Brasileiro de Informática na Educação (CBIE 2016)

aliadas ao processo psicopedagógico, pois possibilitam que o psicopedagogo incentive novas formas de aprender, minimize dificuldades, alivie sintomas propiciando novas relações com a aprendizagem.

As tecnologias têm tido aceitação por parte dos profissionais e são consideradas como uma inovação que pode agregar algo em intervenções, possibilitando aliar aspectos lúdicos, apresentando uma linguagem mais atraente e servindo como apoio e facilitador para intervenções psicopedagógicas, atuando nos processos de ensino e de aprendizagem.

Conclui-se que o uso de tecnologias nas intervenções psicopedagógicas pode ser uma ferramenta auxiliar importante para promover a aprendizagem. É de assinalar que as tecnologias despertam maior interesse, motivação, curiosidade e prazer, aumentando, desta forma, a interação do sujeito na proposta de trabalho. Assim, considera-se que a prática do psicopedagogo aliada ao uso das tecnologias pode contribuir de forma significativa, no aprendizado, atuando como um componente lúdico e facilitador nas intervenções contemporâneas.

\section{Referências}

BENFICA, P. N., FOOHS, M. O uso das ferramentas midiáticas na língua portuguesa. (p. 364 - 384). Objetos de Aprendizagem: teoria e prática. Org.: Liane Margarida R. Margarida R. Tarouco, Bárbara G. Ávila, Edson Félix dos Santos, Marta RoseclerBaz e Valeria Costa. Porto Alegre: Evangraf, 2014. 504 páginas.

BOSSA, N. A psicopedagogia no Brasil: contribuições a partir da prática. Porto Alegre: Artmed, 2007.

FiSTAROL, D. O., COUTINHO, H. R., CANTERO, S. V. A. B., CASTRO JR, A. A. Impactos do Programa NERDS da Fronteira para a Consolidação do Uso das TICs na Educação em Ponta Porã. In Anais do XIX Workshop de Informática na Escola (WIE, 2014), p. 218 - 222. Disponível em: http://www.brie.org/pub/index.php/wie/article/view/3103/2611 Acesso em: 21/04/16.

JESUS, R. J., PASSOS, M. L. S., NOBRE, I. A. M. O Uso do Jogo Migrando e do Google Earth no Ensino de Geografia para alunos do Ensino Médio. In: Anais do XXI Workshop de Informática na Escola (WIE 2015) p. 167 - 176. Disponível em: http://www.br-ie.org/pub/index.php/wie/article/view/5014/3424 . Acesso em: 14/03/16.

KENSKI, V. M. Tecnologias e ensino presencial e a distância. Campinas, SP: Papirus, 2012.

PAIN, S. Diagnóstico e tratamento dos problemas de aprendizagem. Tradução: Ana Maria Netto Machado. $3^{\text {a }}$ Ed. Porto alegre: Artes Médicas, 1989.

REAL, L. M. C.; CORBELLINI, S. Trabalho de conclusão de curso (TCC) em um curso de graduação modalidade EAD: uma proposta cooperativa construída em um ambiente a distância. Revista Novas Tecnologias na Educação (UFRGS, online), v. 9, $\mathrm{N}^{\circ} 1,2011$, p. 17-27. 
V Congresso Brasileiro de Informática na Educação (CBIE 2016)

Anais dos Workshops do V Congresso Brasileiro de Informática na Educação (CBIE 2016)

VALENTE, J. A. Diferentes usos do computador na educação. Em J. A. Valente (org.) Computadores e Conhecimento: repensando a educação. Campina, SP: Gráfica da UNICAMP, 1993.

YIN, R. K. Estudo de caso: planejamento e métodos. $3^{\circ}$ Ed. Porto Alegre: Bookman, 2010 . 